\title{
ПРЕСТУПЛЕНИЯ В СФЕРЕ ВЫБОРОВ ПО УГОЛОВНОМУ ЗАКОНОДАТЕЛЬСТВУ ГЕРМАНИИ, АВСТРИИ И ШВЕЙЦАРИИ
}

\section{(C) 2013 г. Владислав Вячеславович Красинский 1}

\begin{abstract}
Краткая аннотация: в статье рассмотрены преступления в сфере выборов по уголовному законодательству Германии, Австрии, Швейиарии.

Annotation: in article are considered electoral crimes by the criminal legislation of Germany, Austria, Switzerland.

Ключевые слова: избирательный прочесс, преступления в сфере выборов, уголовное законодательство, подкуп избирателей, фальсификаиии на выборах, нарушение тайны голосования.
\end{abstract}

Key words: electoral process, electoral crimes, the criminal codes, bribery of voters, falsifications on elections, violation of secret of vote.

По завершении федеральных избирательных кампаний 2011-2012 гг. в Российской Федерации прокатилась волна протестов граждан, связанные с обвинениями представителей власти в коррумпированности, игнорировании потребностей населения, массовых нарушениях избирательных прав граждан. Прошедшие выборы не только актуализировали проблему отчуждения народа и власти, проблему подлинной демократизации российской политической системы, но и акцентировали внимание на защите политических прав граждан, совершенствовании правовых механизмов ответственности за нарушения законодательства о выборах. В этой связи представляет интерес зарубежный опыт криминализации посягательств на избирательные права участников выборов, а также борьбы с преступлениями в сфере выборов.

Предметом этой статьи является анализ уголовного законодательства ФРГ, Австрии и Швейцарии об ответственности за преступления в сфере выборов.

По законодательству Германии преступления в сфере выборов (§ 107-108 “е” УК ФРГ) включены в гл. 4 Особенной части Уголовного кодекса "Преступления против конституционных органов, а также преступления на выборах и при голосованиях" (Straftaten gegen Verfassungsorgane sowie bei Wahlen und Abstimmungen $)^{2}$.

\footnotetext{
1 Эксперт Российского общественного института избирательного права (РОИИП), член Научно-методического консультативного совета при ЦИК России, доктор юридических наук (E-mail: vkr@fromru.com).

${ }^{2}$ Strafgesetzbuch vom 15. Mai 1871. Neugefasst durch Bek. v. 13.11.1998. Zuletzt geaendert durch Art.1 v. 25.06.2012// http: // www.gesetze-im-internet.de/stgb/index.html
}

К ним относятся: “воспрепятствование проведению выборов" (§ 107), “фальсификация результатов выборов” (§ 107a), “фальсификация избирательных документов” (§ 107b), “нарушение тайны голосования” (§ 107c), “оказание давления на избирателей” (§ 108), “введение избирателей в заблуждение" (§ 108a), "подкуп избирателей" (§ 108b) и “подкуп депутатов” (§ 108e).

Особенность уголовного законодательства Германии, устанавливающего ответственность за преступления в сфере выборов, заключается в том, что в конструкции некоторых составов (§ 107, 107a, 108, 108a) прямо предусмотрена наказуемость покушений на соответствующие преступления ${ }^{3}$.

Объективная сторона “воспрепятствования проведению выборов” (§ 107) связана с “воспрепятствованием с помощью насилия или угрозы применения насилия проведению выборов или установлению их результата". За такие деяния может быть назначено наказание в виде лишения свободы на срок до 5 лет или денежного штрафа. В особо тяжких случаях наказание в виде лишения свободы не может составлять менее 1 года.

В соответствии с ч. 1 § 107а “фальсификация результатов выборов” тот, “кто голосует без соответствующего права или другим образом приводит к неправильному результату выборов или фальсифицирует результат голосования, наказывается лишением свободы до 5 лет или денежным штрафом". Часть 2 данного состава признает на-

\footnotetext{
${ }^{3}$ В германском законодательстве наказуемыми признаются покушения только на наиболее опасные преступления, о чем указывается в соответствующей норме Особенной части УК ФРГ.
} 
казуемыми неправильное объявление результатов выборов или попустительство подобному объявлению результатов выборов. Лицо, которое опубликовало или позволило опубликовать неправильные данные о результатах выборов, привлекается к уголовной ответственности.

Фальсификация избирательных документов (§ 107b) предполагает несколько форм: “регистрация в списке избирателей (выборной картотеке) с помощью недостоверных сведений” (п. 1 ч. 1); “внесение в качестве избирателя гражданина, не имеющего права на регистрацию в списке избирателей” (п. 2 ч. 1); “сознательное воспрепятствование регистрации лица, имеющего право голоса в качестве избирателя" (п. 3 ч. 1); “регистрация в качестве кандидата на выборах лица, не обладающего пассивным избирательным правом" (п. 4 ч. 1).

В ч. $2 \S 107 \mathrm{~b}$ закреплено, что “включение в список избирателей соответствует выдаче избирательных документов на первичных выборах в системе социального страхования". Немецкий законодатель распространил сферу действия данного состава на выборы уполномоченных лиц по делам обязательного страхования в случае болезни, производственных травм, профессиональных заболеваний, материнства, беспомощной старости и смерти.

“Нарушение тайны голосования" (§ 107c) предусматривает ответственность тех, “кто умышленно нарушает инструкцию о защите тайны голосования или стремится получить для себя или других лиц сведения о том, как проголосовал какой-либо избиратель". Следует обратить внимание на обязательный признак субъективной стороны состава преступления - умышленную вину субъекта правонарушения. Данное деяние наказывается денежным штрафом или лишением свободы на срок до двух лет.

Бланкетный способ изложения этой нормы в $\S 107$ с предполагает изучение $\$ 33$ Федерального закона о выборах и $\S 45,50,51,56$ Положения о федеральных выборах, содержащих правовые предписания о защите тайны голосования ${ }^{4}$.

В § 108 криминализировано “оказание давления на избирателей”: “Тот, кто вынуждает другого с помощью насилия, угрозы насилия, посредством

\footnotetext{
${ }^{4} \S 33$ Wahrung des Wahlgeheimnisses. Fuenfter Abschnitt des Bundeswahlgesetzes (Stand am 12. Juli 2012) // BGB1. I S. 1501/ 2012; § 45 Stimmzettel, Umschlaege fuer die Briefwahl, §50 Wahlzellen, § 51 Wahlurnen, § 56 Stimmabgabe. Bundeswahlordnung (Stand am 3. Dezember 2008) // BGBl. I S. 2378/ 2008 .
}

злоупотребления служебной или экономической зависимостью или с помощью иного экономического давления осуществлять избирательное право в определенном смысле или мешает избирать, наказывается лишением свободы до 5 лет или денежным штрафом". Особо тяжкие случаи давления на избирателей наказываются лишением свободы на срок от 1 года до 10 лет.

Законодательное оформление правовых норм $\S 108$ УК ФРГ аналогично конструкции ст. 141 УК РФ “Воспрепятствование осуществлению избирательных прав или работе избирательных комиссий”, но включает в себя более узкий перечень противоправных деяний и способов их совершения.

Существует отдельный состав § 108а "Введение избирателей в заблуждение". Согласно ч. 1 данного параграфа “тот, кто с помощью обмана способствует тому, что кто-либо при голосовании ошибается в сущности своего волеизъявления или против своей воли не голосует или осуществляет недействительное волеизъявление, наказывается лишением свободы до 2 лет или денежным штрафом". Покушение на данное преступление также признается наказуемым.

$\S 108 \mathrm{~b}$ УК Германии определяет ответственность за подкуп избирателей. В соответствии с ч. 1 указанного параграфа наказуемым является “обещание или предоставление подарков или иных благ за то, чтобы избиратель не голосовал или голосовал в определенном смысле". Данные деяния предусматривают наказание в виде лишения свободы на срок до 5 лет или денежный штраф. В ч. 2 состава устанавливается наказание за "продажность” избирателей, т.е. “за получение подарков или иных благ за отказ от избирательного права или голосование в определенном смысле".

В $\S 108 \mathrm{c}$ закреплено, что наряду с лишением свободы на срок от 6 месяцев за совершение преступлений, предусмотренных $\S 107,107 \mathrm{a}, 108$ и $108 \mathrm{~b}$, суд может назначить дополнительное наказание в виде лишения права избирать и участвовать в управлении общественными делами путем голосования.

Несмотря на название, состав "подкуп депутатов” (§ 108е) имеет прямое отношение к преступлениям в сфере выборов. В соответствии с диспозицией статьи “тот, кто осуществляет покупку или продажу голосов на выборах или при голосовании в Европейском парламенте, федеральном, земельном или муниципальном органе народного представительства, наказывается лишением свободы на срок до 5 лет или денежным штрафом". 
В составе, предусмотренном $\S 108 \mathrm{e}$ УК ФРГ, указано, что подкуп депутатов может повлечь ограничение правосубъектности в виде лишения избирательного права. Наряду с лишением свободы на срок не менее 6 месяцев суд вправе лишить лицо права избирать и участвовать в управлении общественными делами путем голосования.

Анализ немецкого уголовного законодательства позволяет сделать вывод о казуистическом характере построения норм об ответственности за нарушения избирательного законодательства. По справедливому замечанию И.С. Власова, нормы гл. 4 Особенной части УК ФРГ, закрепляющие составы преступлений в сфере выборов, “построены казуистично, что является их достоинством и свидетельствует о том скрупулезном внимании, которое уделяется законодателем защите этих прав"5.

В Австрии преступления на выборах и референдумах объединены в гл. 18 Уголовного кодекса (§ 261-268) (Strafbare Handlungen bei Wahlen und Volksabstimmungen $)^{6}$.

В число преступлений в сфере выборов входят: "воспрепятствование осуществлению избирательного права” (§ 262), “обман на выборах или всенародном голосовании” (§ 263), “распространение недостоверной информации в ходе выборов или всенародного голосования" (§ 264), “подкуп на выборах или всенародном голосовании” (§ 265), “фальсификация на выборах или всенародном голосовании” (§ 266), “воспрепятствование проведению выборов или всенародного голосования" (§ 267) и "нарушение тайны выборов или всенародного голосования” (§ 268).

Диспозиция состава “воспрепятствование осуществлению избирательного права” § 262 УК Австрии схожа с диспозицией § 108 УК ФРГ “оказание давления на избирателей”. Она объединяет и воспрепятствование голосованию с помощью насилия или опасной угрозы, и оказание давления на избирателей с целью воспрепятствования реализации избирательного права или права голоса. Вместе с тем наказание за совершение подобных деяний в Германии существенно строже (до 5 лет лишения свободы, в особо тяжких случаях - до 10 лет лишения свободы). В Австрии санкция § 262 Уголовного кодекса предусматривает лишение свободы от 6 месяцев до 1 года или

\footnotetext{
5 Ответственность за нарушения избирательных прав граждан в законодательстве зарубежных стран. М., 2005. С. 6.

${ }^{6}$ Strafgesetzbuch vom 1. Januar 1975 (Stand am 1. August 2012) // http://www.jusline.at/index.php?cpid=f04b15af72dbf3fdc07 72f869d4877ea\&law_id=11
}

штраф в размере дохода осужденного за период до 360 дней.

Диспозиция преступления “обман на выборах или всенародном голосовании” § 263 УК Австрии напоминает диспозицию $\S 108$ а УК ФРГ “введение избирателей в заблуждение”. Законодатель устанавливает ответственность за введение в заблуждение, повлекшее ошибочное представление избирателя о сущности своего волеизъявления, или недействительность волеизъявления либо отказ от голосования.

Некоторые российские юристы обосновывают востребованность такого состава, устанавливающего ответственность за дезинформирование избирателей, в УК РФ. Как отмечает Н.Ю. Турищева, “отсутствие аналогичного состава преступления в УК РФ приводит к тому, что остаются без уголовно-правовой оценки подобные акции, непосредственно влияющие на признание выборов недействительными вследствие того, что многочисленные нарушения не позволяют с достоверностью выявить действительную волю избирателей"7.

Специфика австрийского уголовного законодательства в сфере выборов заключается в наличии отдельного состава преступления, устанавливающего ответственность за распространение ложной информации, связанной с проведением выборов или всенародного голосования. Согласно $\S 264$ УК Австрии уголовно наказуемым является публичное распространение ложной информации при условии невозможности фактического опровержения недостоверных сведений. Подобное деяние наказывается лишением свободы на срок до 6 месяцев или штрафом в размере дохода осужденного за период до 360 дней. Квалифицированным признаком является использование фальшивых или поддельных документов для придания достоверности ложной информации. В этом случае данное деяние наказывается сроком до 3 лет лишения свободы.

Данный состав можно было бы ввести в УК РФ. Общественная опасность незаконных требований о непризнании итогов выборов, распространения заведомо ложной информации, связанной с подготовкой и проведением выборов, заключается в том, что такие деяния подрывают доверие граждан к системе избирательных комиссий и госу-

\footnotetext{
${ }^{7}$ Турищева Н.Ю. Преступления против избирательных прав и права на участие в референдуме: уголовно-правовой анализ и перспективы совершенствования законодательного описания: по материалам Краснодарского края. Дисс. ... канд. юрид. наук. Краснодар, 2007.
} 
дарственной власти в целом. Спровоцированные таким образом затяжные политические кризисы всерьез угрожают функционированию конституционных демократических институтов в любом государстве.

Сравнительный анализ состава “подкуп на выборах или всенародном голосовании" § 265 УК Австрии и подкупа избирателей по УК Германии (§ 108b) свидетельствует о схожести формы изложения данных преступлений в статьях австрийского и немецкого уголовных законов. Законодатель криминализировал предложение, обещание и предоставление вознаграждения за голосование или отказ от голосования в определенном смысле. Согласно ч. 2 § 265 УК Австрии также устанавливается уголовная ответственность лиц, обладающих избирательным правом, за их требование, принятие или согласие на получение вознаграждения, связанные с отказом от избирательного права или голосованием в определенном смысле.

В соответствии с $\S 266$ УК Австрии закреплены три формы фальсификации на выборах или всенародном голосовании:

голосование лиц, не обладающих избирательным правом;

голосование от имени других лиц без соответствующего согласия или против их воли;

фальсификация результатов выборов или голосования.

Думается, что анализируемый состав сконструирован не совсем удачно. В Германии противоправным признается более широкий спектр деяний, связанных с фальсификацией выборов или результатов голосования. В частности, в УК Австрии не предусматривается наказания за неправильное объявление результатов выборов (попустительство подобным деяниям) и фальсификацию избирательных документов. Кроме того, не вполне понятно, какие именно деяния квалифицируются как “фальсификация результатов выборов или голосования” (ч. 2 § 266). К числу достоинств австрийского способа изложения элементов норм права в 266 относится включение в конструкцию состава голосования от имени других лиц без соответствующего согласия или против их воли.

Объективная сторона “воспрепятствования проведению выборов или всенародного голосования" (§ 267 УК Австрии) связана с воспрепятствованием с помощью насилия или опасной угрозы проведению выборов, всенародного голосования, определению или объявлению их результатов. Обязательным элементом субъективной стороны данного состава является умышленная форма вины.

Австрийским Уголовным кодексом установлена наиболее мягкая в группе анализируемых государств ответственность за нарушение тайны выборов или всенародного голосования (§ 268). В Германии санкция за нарушение тайны голосования предусматривает до 2 лет лишения свободы, а в Швейцарии - до 3 лет.

В Швейцарии преступления в сфере выборов (ст. 279-283 УК) включены в гл. 14 Особенной части Уголовного кодекса "Преступления против народного волеизъявления" (Vergehen gegen den Volkswillen) ${ }^{8}$.

В ст. 279 "Вмешательство и воспрепятствование проведению выборов и голосований” устанавливается уголовная ответственность для тех, “кто препятствует или мешает с помощью насилия или угрозы причинения серьезного ущерба предписанному конституцией или законом собранию, выборам или голосованию”, а также тех, “кто препятствует сбору или передаче подписей с требованием проведения референдума или какойлибо инициативы с помощью насилия или угрозы причинения серьезного ущерба". Санкция за данные деяния, как и в Австрии, существенно мягче, чем в Германии: законодателем предусмотрено лишение свободы на срок до 3 лет или денежный штраф.

Диспозиция ст. 280 “Вмешательство в право голосовать и избирать” криминализирует деяния, мешающие избирателю осуществлять свои права: голосовать, избирать, участвовать в референдуме или осуществлении инициативы с помощью силы или угрозы причинения серьезного ущерба. В соответствии с данной статьей также наказываются лица, которые “оказывают давление на избирателя с помощью силы или угрозы причинения серьезного ущерба, связанное с осуществлением в целом или в определенной части перечисленных политических прав"9. Совершение подобных деяний наказывается лишением свободы на срок до 3 лет или денежным штрафом.

Ответственность за подкуп избирателей предусматривается ст. 281 УК Швейцарии.

Конструкция состава признает преступными действия:

\footnotetext{
${ }^{8}$ Schweizerisches Strafgesetzbuch vom 21. Dezember 1937 (Stand am 16. Juli 2012) // http://www.admin.ch/ch/d/sr/311_0/ index $2 . \mathrm{html}$

${ }^{9}$ Необходимо отметить, что “оказание давления на избирателей” является самостоятельным составом преступления в УК ФРГ (§ 108).
} 
тех, кто “предлагает, обещает, дает или доставляет какому-либо избирателю подарок или другие блага, чтобы тот голосовал или избирал определенным образом, присоединился либо отказался от участия в референдуме или осуществлении какой-либо инициативы”;

тех, кто “предлагает, обещает, дает или доставляет какому-либо избирателю подарок или другие блага, чтобы тот не участвовал в проведении выборов или голосования";

тех, кто “позволил пообещать или дать себе подобные блага в качестве избирателя”.

Как и в УК Австрии (ч. 2 § 265), в швейцарском уголовном законе устанавливается наказуемость принятия или согласия на получение вознаграждения (других благ), связанных с отказом от избирательного права, участием в выборах или голосованием в определенном смысле.

В ст. 282 УК Швейцарии закреплены следующие формы фальсификации результатов выборов:

фальсификация, подделка или уничтожение списков избирателей;

участие в выборах, голосовании, референдуме или осуществлении инициативы без соответствующего права;

фальсификация результатов выборов, голосования или собрания по сбору подписей для проведения референдума или осуществления инициативы.

Включение в объективную сторону состава "фальсификация результатов выборов" уничтожения избирательных документов (списков избирателей) является особенностью швейцарского уголовного законодательства в сфере выборов.

Законодатель закрепляет конкретные способы фальсификации результатов выборов, голосования или собрания по сбору подписей: с помощью добавления, изменения, пропуска или вычеркивания сведений из бюллетеней для голосования или подписных листов; с помощью неправильного подсчета голосов или недостоверного оглашения результатов.

В ч. 2 комментируемой статьи содержится квалифицирующий признак - наличие специального субъекта преступления: лица, действующего в официальном качестве. В этом случае наряду с лишением свободы на срок до 3 лет судом может быть назначено дополнительное наказание в виде денежного штрафа в размере дохода осужденного за период не менее 30 дней.
Еще одной особенностью уголовного законодательства Швейцарии в сфере выборов является криминализация действий, связанных с планомерным сбором, заполнением, обменом и раздачей избирательных бюллетеней (бюллетеней для голосования) (ст. 282.2). Такие действия (“охота за голосами избирателей”) считаются наказуемыми независимо от получения за них вознаграждения (других благ).

В ст. 283 УК Швейцарии "Нарушение тайны голосования и тайны выбора" установлена ответственность за незаконное добывание сведений о том, как голосуют или избирают определенные избиратели. Формулировка диспозиции статьи подразумевает возможность легального доступа уполномоченных органов (должностных лиц) Швейцарии к сведениям о волеизъявлении избирателей, что противоречит самому принципу тайного голосования.

Уголовное законодательство Лихтенштейна копирует УК Австрии ${ }^{10}$. Преступления на выборах и референдумах объединены в гл. 18 Уголовного кодекса Лихтенштейна (§ 261-268) и дословно воспроизводят содержание соответствующих правовых положений УК Австрии.

Сравнительно-правовой анализ составов преступлений в сфере выборов по уголовному законодательству Германии, Австрии и Швейцарии позволяет сделать следующие основные выводы об уголовно-правовой политике данных государств.

Наибольшее количество составов преступлений в сфере выборов закреплено в УК ФРГ (8). Германское уголовное законодательство содержит и наиболее строгие санкции за совершение преступлений в сфере выборов: предусмотрены наказуемость покушений на соответствующие преступления и лишение избирательного права как мера наказания.

Австрийский уголовный закон в сравнении с германским и швейцарским более мягко наказывает подкуп избирателей, вмешательство в осуществление избирательного права, нарушение тайны выборов или всенародного голосования. УК Австрии, в отличие от законодательства ФРГ и Швейцарии, не предусматривает наказания за неправильное объявление результатов выборов (попустительство подобным деяниям) и фальсификацию избирательных документов. В то же время в Австрии и Лихтенштейне установлена уголовная ответственность за распространение

\footnotetext{
${ }^{10}$ Strafgesetzbuch vom 24. Juni 1987 // Liechtensteinisches Landesgesetzblatt. 1988. Nr. 37.
} 
ложной информации, связанной с проведением выборов или всенародного голосования, при невозможности опровержения недостоверных сведений.

В швейцарском УК (ст. 283) подразумевается возможность легального доступа уполномоченных органов (должностных лиц) к сведениям о волеизъявлении избирателей, что противоречит самому конституционно-правовому принципу тайного голосования.

В этих государствах законодатель криминализировал посягательства на финансирование выборов: подкуп избирателей выделен в самостоятельный состав преступления (§ 108 “b” УК ФРГ, $\S 265$ УК Австрии, ст. 281 УК Швейцарии), а получение избирателями (участниками референдума) выгоды за осуществление волеизъявления является признаком квалифицированного состава “подкуп избирателей”.

Особенностью уголовно-правовой политики Германии, Австрии и Швейцарии по защите кон- ституционного строя в избирательном процессе является наличие ряда специфических составов преступлений в сфере выборов, не имеющих аналогов в других государствах (§ 108 “e” УК ФРГ “подкуп депутатов”, § 264 УК Австрии "распространение недостоверной информации в ходе выборов или всенародного голосования" и ст. 282.2 УК Швейцарии “охота за голосами избирателей”).

Положительный зарубежный опыт уголовноправовой политики указанных государств можно было бы заимствовать и российскому законодателю. Введение уголовной ответственности за подкуп избирателей и депутатов, получение избирателями (участниками референдума) выгоды за осуществление волеизъявления, а также за распространение ложной информации, связанной с проведением выборов или всенародного голосования, является своевременным и адекватным правовым средством защиты демократических институтов и норм избирательного права. 